\title{
Epidemiology of Pediatric Tumours at a Tertiary Care Centre
}

\author{
A.K. RATHI, SAURABH KUMAR, ABHISHEK ASHU, K SINGH AND \\ A.K. BAHADUR
}

\section{ABSTRACT}

Background: Pediatric malignancies are on rise. We studied pattern of pediatric tumours in our department.

Methods: Between January 1996- December 2005 data was analyzed for the tumours occurring in the age group 0-14 years. Data was categorized according to incidence of pediatric tumour per year and in different age groups. The results were compared with Indian and International data.

Results: There were 18440 cases, of which 624 were pediatric tumours; Overall incidence of pediatric tumours was $3.38 \%$. Males were affected more than females. Brain tumours were. Most common followed by hematological malignancies and Retinoblastoma in order of decreasing frequency.

Conclusion: The study shows difference between pooled data and that from a tertiary center in terms of incidence of various pediatric tumours. The study emphasizes the role of registry maintenance for pediatric tumours in developing world.

$\overline{\text { Department of Radiotherapy and Oncology, Maulana Azad }}$ Medical College and Associated Lok Nayak Hospitals New Delhi 11002

Coresspondence to: SAURABH KUMAR

E-mail-drsaurabhkumar@gmail.com

\section{INTRODUCTION}

Incidence of pediatric tumours is on rise all over the globe. Malignancy is the second most common cause of childhood death in developed world, accounting for $12.3 \%$ of all childhood deaths in U.S.A. ${ }^{1}$

Although major cause of childhood mortality in developing world is still malnutrition and infections, pediatric tumours are also rising in numbers. Appropriate management of pediatric tumours requires complete epidemiological data of pediatric tumours in different geographical areas. As hospital registries are the only available source of information for assessing the disease pattern in community, we conducted this retrospective study based on our hospital records of past ten years.

\section{MATERIALS AND METHODS}

The hospital records of past ten years (January 1996- December 2005) were analyzed for tumours occurring in age group 0-14 years. Histological classification system used was the one proposed by Birch and Marden. ${ }^{2}$ The data so obtained was arranged according to incidence per year, incidence of various tumours according to age and sex. The data was compared with population based cancer registry from India and U.S.A. 


\section{RESULTS}

There were eighteen thousand four hundred and forty cases, of which six hundred and twenty four were pediatric tumours. The pediatric tumours comprised of $3.38 \%$ of all malignancies. Males were affected more than females, there were $453 / 624$ male cases compared to $171 / 624$ in females yielding male to female ratio of 2.64 . Year- wise incidence of pediatric tumours was deduced as shown below in graph 1 .

Tumours were arranged according to their incidence in 0-4 year, 5-9 year and 10-14 year age group. malignancies, comparable to Indian data ${ }^{3}$ $(3.58 \%)$ the proportion of childhood cancers seems to be high compared to that of developed countries. Males were affected more than females $(72.6 \% \text { Vs } 27.4)^{3}$, comparable to results from other registries. Brain tumours were the most common malignancy affecting $31.08 \%$ of children in our study and $27.8 \%$ of all brain tumours were astrocytomas. Second most common brain tumour was medulloblastoma affecting $21.6 \%$ of children. Ninety one percent of astrocytomas occurred in age $>5$ years. The brain tumours had high incidence in our study due to increased referral.

The result in terms of individual brain tumour incidence was comparable to published data. ${ }^{3,4}$

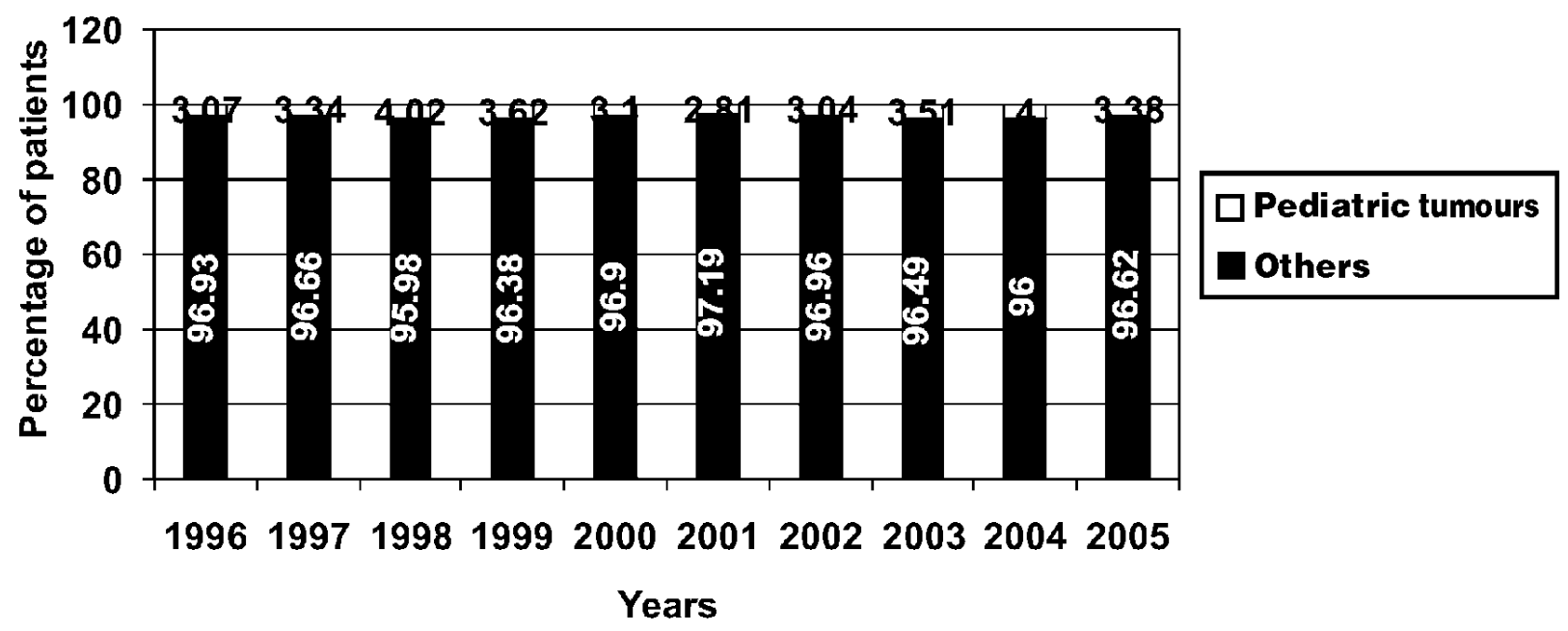

The incidence of tumours varied among different age groups, retinoblastoma was commonest tumour in 0-4 year age group, whereas brain tumours were most common tumours in 5-9 and 10-13 year age groups. The data was compared with Indian and international registries (Table-1)

\section{DISCUSSION}

Incidence of pediatric tumours is on rise. In our study pediatric tumours constituted $3.4 \%$ of all
Hematological malignancies were the second most common affecting $18.1 \%$ of children. Hodgkin's disease was most common hematological malignancy comprising $38.9 \%$ of all hematological malignancies with maximum incidence in 10-14 years age group. Acute lymphoblastic leukaemia was the second most common malignancy comprising of $34.5 \%$ of all hematological malignancies. Studies in literature show acute lymphoblastic leukaemia to be the most common childhood malignancy ${ }^{3,4}$ 
Table 1. Incidence of childhood tumours comparison with Indian ${ }^{3}$ and U.S. ${ }^{4}$ data

\begin{tabular}{|l|l|l|c|}
\hline & Present Study & INDIA (3) & USA (4) \\
\hline LEUKAEMIA & 6.57 & 32 & 30.2 \\
\hline LYMPHOMA & 11.58 & 14.08 & 10.88 \\
\hline CNS & 31.08 & 18.21 & 20.96 \\
\hline SNS & 2.56 & 4.21 & 8.23 \\
\hline RETINOBLASTOMA & 14.10 & 4.02 & 3.04 \\
\hline RENAL & 4.16 & 4.94 & 6.32 \\
\hline HEPATIC & 0.96 & 1.41 & 1.29 \\
\hline BONE & 8.33 & 4.67 & 4.65 \\
\hline STS & 11.85 & 5.49 & 6.95 \\
\hline GCT & 1.12 & 2.99 & 3.28 \\
\hline OTHERS & 4.8 & 7.12 & 3.70 \\
\hline OTHER CARCINOMA & 2.88 & 5.8 & 0.41 \\
\hline
\end{tabular}

but the incidence of leukaemia was low in our centre due to lack of hemato-oncology department in our hospital.

Retinoblastoma was the third most common childhood tumour affecting $14 \%$ of study population. High incidence of retinoblastoma was in contrast to other studies ${ }^{3,4}$, which may be due to state of the art department of Ophthalamology attached to our centre.

Tumours showed wide incidence variation among the age groups. Frequency of Retinoblastoma, CNS tumours, soft tissue tumours, hematological tumours and renal tumours was high in children $<4$ years of age. In children $>4$ years CNS, lymphomas, soft tissue sarcomas were most common.

Pediatric tumours are a special entity with different genetic, environmental factors playing role in their etiology. The growth potential and response to treatment is also different from those of adult tumours. Children in developing nations are increasingly affected by malignancy in addition to rampant malnutrition and infections, but dedicated registry maintenance of pediatric tumours is lacking. As many of common childhood malignancies are curable there is a need to have a dedicated pediatric cancer registry for assessing the magnitude of problem in our country as pediatric tumours show wide variations across centres as shown in our study.

\section{REFRENCES:}

1. Jemal Ahmedin, Siegel Rebecca, Ward Elizabeth et al Cancer Statistics, 2006 CA Cancer J Clin 2006;56:106130 .

2. Birch JM, Marsden HB. A classification scheme for childhood cancer. Int J Cancer 1987;40:620-624.

3. National Cancer Registry Programme, India 1996-1997 Indian councial of Medical Research, New Delhi.

4. Martha S. Linet, Lynn A. G. Ries, Malcolm A. Smith, Robert E. Tarone, Susan S. Devesa. Cancer Surveillance Series: Recent Trends in Childhood Cancer Incidence and Mortality in the United States, J. Nat1 Cancer Inst. 1999;91:1051-1058. 